\title{
THE PETAWAWA UNEMPLOYMENT RELIEF PROJECT
}

\author{
By \\ R. H. CANDY \\ Dominion Forest Service
}

S one part of its general programme for the relief of unemployment in
Canada, the Federal Government undertook to take care of the single,
physically fit, homeless men unable to secure employment. The under
taking included the provision of shelter, food, clothes and healthful work to
these men who, through no fault of their own, have lost their means of
support as a result of the depression, and who have not otherwise been
provided for.

The aim is to employ these men on work that will be of benefit to the nation as a whole and will at the same time keep them in a healthy condition and prevent a lowering of their morale through lack of nourishment and the waning of hope and encouragement, so that on return of normal conditions they may be morally and physically fitted to resume their various occupations without undue delay.

Unemployment relief camps for single homeless men have been established in National Parks under the Department of the Interior, and elsewhere under the direction of the Department of National Defence. My remarks will deal especially with the National Defence Department camps. From one end of the Dominion to the other a large number of camps have been established as bases for carrying on a variety of projects, including aeroplane landing felds, repair and restoration of historic sites, the improvement of facilities at military training depots, and the construction of roads and other works.

Recognizing the advantages which lay in giving men employment in the woods, the Department of National Defence offered the facilities of this organization for the advancement of construction and improvement pro. grammes at forest experiment stations. In the suggestion, the Forest Service, Department of the Interior, discerned an excellent opportunity for augmenting and greatly improving its facilities at such stations. The initial steps in this direction were taken about a little less than one year ago.

At the present time work of this character is being carried on at the Petawawa Forest Experiment Station, situated in the Ottawa valley, a few miles above Pembroke. Similar operations are under way at the Valcartier Porest Experiment Station, north of Quebec City. A new station to serve as a base of forest research operations in the Maritimes has been established in the province of New Brunswick, a few miles northeast of Fredericton. To serve 
as a base station for forest research and investigations in the Prairie Provinces, a new station has been established in the Duck Mountain Forest Reserve in the province of Manitoba.

In the establishment of these two new stations, the provincial governments of New Brunswick and Manitoba co-operated splendidly, by making available the lands required. Although not as yet finally completed, arrange. ments have also been under way for the establishment of a similar station at Thurlow Island in British Columbia, about 125 miles north of Vancouver.

It is with the relief operations at Petawawa Forest Experiment Station that I have been asked to deal. With the foregoing general remarks, I shall now confine myself to the work with which I have been directly connected.

During the spring of 1933 about one thousand men arrived at Petawawa. The men were recruited largely from the City of Montreal. Many of them, on their arrival, clearly showed the effect of under-nourishment and lack of clothing. They had, prior to the depression, been engaged in a wide variety of occupations. A very large number had never engaged in forest activities of any kind. Some of them were in the forest areas for the first time. However, a fair number of them were experienced bushmen who proved themselves extremely useful, particularly through the breaking-in period of those less experienced.

On arrival, and where required, the men were outfitted with suitable clothing and accessories; they were housed in buildings or tents; fed on the basis of army rations; and given an allowance of twenty cents per working day and a small tobacco allowance.

About half of the men were assigned to work in building huts, constructing a landing field for aeroplanes, the manufacture of cement blocks and other work of this character. The other half were assigned work in planting trees, building forest roads, and cutting timber and sawing lumber, the lumber to be used in the erection of buildings on the reserve or for shipment to other nearby employment projects.

The road construction, planting and logging conducted on the forestry experimental area were under the direct supervision of forest officers. For the plantation work about 700,000 four-year-old trees were very kindly provided by the Ontario Forestry Branch, which organization also co-operated in supplying of equipment and assisting in organization. The trees were planted in areas previously burned over, which were not restocking naturally.

Roads were laid out with a view to augmenting the facilities for transportation for fire protection and experimental purposes; also for the purpose of opening-up for proper forest management areas which were partly or wholly inaccessible. This improved system of transportation will be of great 
assistance in carrying out the working plans which have been prepared for this reserve.

While the amount of work completed during the season was not all that had been hoped for, the quality of it was better than had been expected. In spite of the fact that planting operations were followed by the driest June on our records at the Station, mortality at the end of the year did not exceed 20 per cent, and now that plants are well established an excellent stand seems to be fairly well assured.

Some excellent roads have been built, some of them having a crown of 12 feet in width, others 18 feet. Bridges and culverts have been built in a first class manner and a bridge about 280 feet in length, capable of carrying a five-ton-truck, is almost completed across the Petawawa river. These few examples illustrate what can be undertaken by this class of labor with a minimum of equipment.

Areas have been set aside under the provisions of our working plan and will be logged under methods most suitable for experimentation. Cutting areas are carefully demarcated and the individual trees marked for cutting previous to the actual logging. The cutting block is divided into areas on which clearcutting, strip cutting and various selection methods will be followed, thus enabling the Service to make a scientific yet practical study of the results secured under the various methods of silvicultural treatment. Basically, these cutting operations are for the purpose of securing timber required for the numerous and various construction projects being carried out. We are, however, taking full advantage of the opportunity afforded to study the results of several methods of silvicultural practice.

With the experience gained during the past season, it may definitely be expected that greater progress will be made in future operations. As this work is being undertaken at the Petawawa Forest Experiment Station its value from a demonstration standpoint may well be perceived. The results secured under the various methods may be viewed by foresters and others interested in the progress and development of forest industry. Of particular interest are the two saw mills owned by the project which, with the exception of key men, are run entirely by inexperienced labour.

As a measure of unemployment relief, it is obvious to any person connected with this work that the men show great improvement in their condition. They have put on weight and have improved in health. I could give many instances of this favourable change. Of course, they are in these camps as a result of economic necessity; things being as they are, these men are happier, healthier and in a much better moral and physical condition than they would be doing nothing or wandering aimlessly from city to city. 
The amount of work done by these men is with few exceptions reasonable. No pretence is made that work should in any way resemble contract labour. They have not got the costly equipment, and it would not be reasonably to expect that they would work as hard as fully paid labour. In addition, a large number of men engaged on forest operations, road building, etc., have never had previous experience. Many of the men are clerks, store keepers, taxi drivers and elevator operators.

I have seen a Cambridge graduate and a messenger handling an axe under the direction of a sub-boss who had formerly been the base of a pyramid in a circus. I have seen men working with a fair degree of efficiency on a saw-mill who had never previously seen a saw-mill except from a train or car. The whole project calls for patience and tact, not comparison or criticism. As time progresses, the amount of work done is quite considerable. Men work well, particularly if the work seems useful and they see that progress is being made. This psychological factor is, in my opinion, so important that $I$ think even more consideration might be given to it. Men should have the objects, and value of the work explained to them. In addition, I believe that men should be given more equipment to work with so that they may be encouraged by the more rapid accomplishment of results of their labour.

In addition to affording relief to unemployed men, the work done so far, and all work which it is planned to undertake, constitutes a capital investment which will yield a fair return in future years. The return that will result from planting up barren areas is too obvious for further comment; the thinning of dense stands of softwoods, hardwoods, and the removal of hardwoods and undesirable trees for fuelwood, will give good returns in improving quality of stand and in the rapid increase in the rate of growth that will follow such thinnings.

The construction of roads, I believe, is a crying need in the forests which lie within a reasonable distance of fair-sized settlements and markets. Such roads not only aid in their protection from fire, but assist in the exploitation of areas where the removal of certain species would otherwise prove unprofitable. I refer more particularly to hardwood areas. Most members of the forest industry are aware of the difficulties facing the industry through the suppression of valuable conifers by hardwoods, a condition brought about by the practice of continuously removing softwoods from mixedwood stands, and the resulting steady increase of the percentage of hardwood stands in most of our forests.

It has long been realized that some method is desirable whereby more hardwoods may be removed. In my opinion the construction of these roads, 
is the greatest contribution made towards solution of this problem. At Petawawa the execution of our working plan will be simplified enormously by the construction of these roads; for, with them the removal of intolerant and other hardwoods becomes economically feasible. Moreover, the removal of these hardwoods will maintain the forest in a more balanced condition.

From the foregoing remarks it will be seen that the Forest Service is simply taking proper advantage of the facilities offered under the unemployed relief projects to advance so far as possible the interests and work at the Forest Experiment Station. In ordinary times, it is extremely difficult to get sufficient funds for the provision of improvements adequate for the protection. and administration of these areas. In hard times, it is even more difficult to do so. The relief projects therefore offered a splendid opportunity to get installed, in a relatively short time, a system of improvements which would not otherwise have been possible.

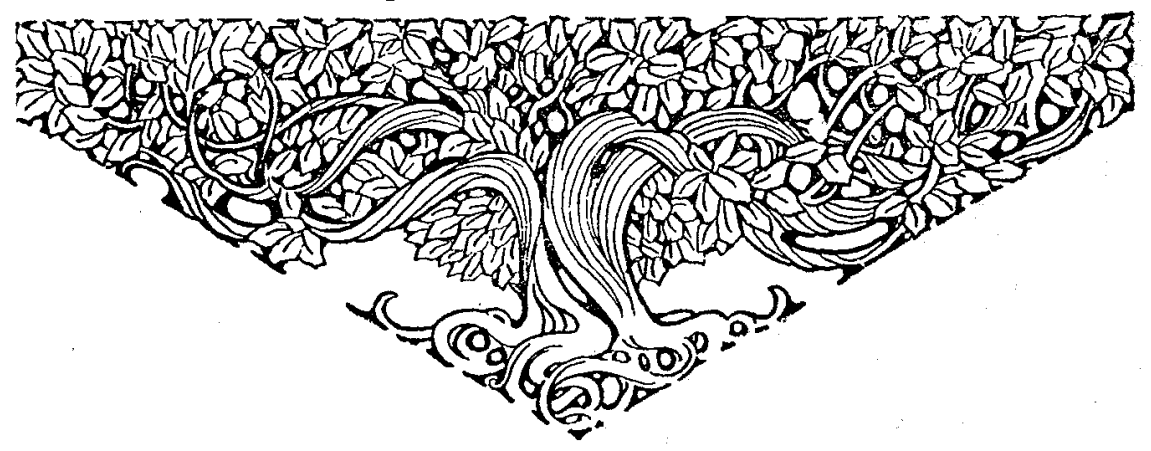

